J.P. Liu · J.D. Milliman · S. Gao

\title{
The Shandong mud wedge and post-glacial sediment accumulation in the Yellow Sea
}

Published online: 6 February 2002

(C) Springer-Verlag 2002

\section{Geo-Mar Lett (2002) DOI s00367-001-0083-5}

Fig. 3 was given incorrectly and the revised version is reproduced here. dx.doi.org/10.1007/s00367-001-0083-5

J.P. Liu $(\bowtie) \cdot$ J.D. Milliman

School of Marine Science,

College of William and Mary,

Gloucester Point, VA 23062, USA

E-mail: jpliu@vims.edu

Tel.: + 1-804-684-7739

Fax: + 1-804-684-7250

S. $\mathrm{Gao}^{1}$

Institute of Oceanology,

Chinese Academy of Sciences, Qingdao 266071, China

Present address:

${ }^{1}$ Department of Geo-Ocean Science,

Nanjing University, Nanjing 210093, China

e-mail: shugao@nju.edu.cn 



$\mathrm{N}$

S



Fig. 3 Selected high-resolution seismic profiles from the North and South Yellow seas, showing the clinoform morphology of the Shandong mud wedge which overlies a well-developed reflector. Biogenic gas obscures the internal reflector in the thicker portion of the mud wedge (see locations in Fig. 2c). Vertical scale: $10 \mathrm{~ms}$ twoway travel time $=8.0 \mathrm{~m}$ ). Core NYS-5 at the toe of the bottomset strata in profile $99-\mathrm{F}$ shows mud overlying a peat layer whose age is $11.8 \mathrm{ka}$ (Table 2) 